\title{
GAMBARAN PENGETAHUAN DAN KUALITAS HIDUP LANJUT USIA YANG MENGGUNAKAN GIGI TIRUAN DI DESA SIBUAK KECAMATAN TAPUNG KABUPATEN KAMPAR TAHUN 2015
}

\author{
Jihan Natassa dan Zulhidriani
}

\author{
jihannatassa@yahoo.co.id
}

\begin{abstract}
The elderly must be use the denture to complete the needs of good life functionally and optimally. This research aims to determine the description of Knowledge and Life Quality Of Elderly Who Use The Denture at Sibuak Village, Tapung, Kampar In 2015. Type of this research is descriptive. The population of the elderly at Sibuak Village, Tapung, Kampar are 45 person. The sampling technique is total sampling technique. The method of data collection is questionnaire. The data is processed by a computer program and presented in frequency distribution table. Then, the results showed the most of the elderly respondents who use the denture about 6074 years are 31 person (68.9\%), the majority of female respondents are 28 person $(62.2 \%)$, the majority of respondents with elementary education level are 21 person (46.7\%), the majority of housewife respondents are 21 person (46.7\%), the majority of GTLL denture types respondents are 23 person (51.1\%), and a good level of knowledge of the majority of respondents are 23 person (51.1\%), also the low quality of life respondents are 26 person (57.8\%). Based on the results, the elderly should be more attention and take care for their oral cavity, they also can give the information about denture benefits to others. For sure, the dentist or dental health workers should lead the others to take care their oral cavity especially for edentolus patients, so they can reach a better life quality functionally and optimally.
\end{abstract}

\section{Keywords : Knowledge, Life Quality, Denture}

\section{PENDAHULUAN}

Dalam memasuki era abad ke-21 jumlah kelompok usia lanjut (lansia) diseluruh dunia meningkat termasuk di Indonesia. Menurut lembaga Demografi FE-UI pada tahun 2000 jumlah lansia di Indonesia yang berumur 60 tahun ke atas berkisar 7,6\% dan pada tahun 2020 akan mencapai 11.6\% (Boedhi dan Darmojo, 2010).

Menua merupakan proses yang terjadi terus menerus secara alami. Proses menua cendrung menimbulkan masalah kesehatan secara umum maupun kesehatan jiwa secara khusus pada manula (Rawiyah, 2014).

Menjadi usia lanjut merupakan suatu proses alamiah yang berarti seseorang telah melalui tiga tahap kehidupannya yaitu masa anak-anak, dewasa dan usia lanjut. Memasuki masa usia lanjut berarti mengalami kemunduran, seperti kemunduran fisik yang ditandai dengan kulit yang mengendor, rambut memutih, sebagian atau seluruh gigi hilang, penglihatan semakin menurun, pendengaran kurang, gerakan lamban dan figur tubuh yang tidak proporsional (Boedhi dan Darmojo, 2010).
Seiring dengan bertambahnya usia, banyak lansia yang kehilangan giginya sehingga menimbulkan efek pada rongga mulut. Salah satu efek yang ditimbulkan seperti terganggunya sistem mastikasi, penurunan kemampuan seseorang untuk makan, bicara dan sebagainya. Oleh sebab itu, pasien yang mengalami kehilangan gigi harus segera diberi perawatan prostodontik untuk mencegah terjadi kerusakan lebih lanjut. Akan tetapi kesadaran yang muncul untuk melakukan kunjungan kedokter gigi seseorang terhambat dengan adanya faktor-faktor lain seperti ketersediaan waktu, ketidaknyamanan, kecemasan saat berada di praktek dokter gigi dan pertimbangan biaya. Faktor-faktor tersebut secara tidak langsung akan mempengaruhi frekuensi kunjungan dan alasan datang ke dokter gigi.

Hal tersebut berbanding terbalik dengan keinginan lansia untuk mendapatkan kualitas hidup yang lebih baik seperti dapat memperbaiki fungsi bicara, meningkatkan fungsi pengunyahan, dan memperbaiki fungsi estetis dengan cara memakai gigi palsu melalui jasa tukang gigi. Dalam pembuatan gigi tiruan 
tidak semua dapat berhasil atau berfungsi dengan baik karena terdapat keluhan-keluhan dari pemakai gigi palsu terutama lansia.

Gigi tiruan adalah suatu alat yang berfungsi untuk menggantikan sebagian atau seluruh gigi asli yang hilang dan digunakan pada rahang atas maupun rahang bawah. Meskipun kemajuan dalam bidang estetika kedokteran gigi sangat pesat namun fungsi gigi geligi itu sendiri tetap di dukung oleh kondisi fisik seseorang (Haryanto, 1991).

Seiring dengan banyaknya pemasangan gigi palsu pada lansia yang ingin merubah kualitas hidup menjadi lebih baik, hal tersebut juga terjadi di Desa Sibuak Kecamatan Tapung Kabupaten Kampar yang memiliki 568 kepala keluarga.

Berdasarkan latar belakang tersebut maka peneliti tertarik untuk mengetahui Gambaran Pengetahuan Dan Kualitas Hidup Lanjut Usia Yang Menggunakan Gigi Tiruan Di Desa Sibuak Kecamatan Tapung Kabupaten Kampar Tahun 2015.

\section{METODOLOGI PENELITIAN}

Jenis penelitian ini adalah kuantitatif. Penelitian kuantitatif merupakan salah satu jenis penelitian yang spesifikasinya adalah sistematis, terencana, dan terstruktur dengan jenis ini, dari sejak awal hingga pembuatan desain penelitiannya. Penelitian menggunakan desain penelitian deskriptif untuk mendapatkan gambaran pengetahuan dan kualitas hidup lanjut usia yang menggunakan gigi tiruan. Lokasi penelitian dilakukan di Desa Sibuak Kecamatan Tapung Kabupaten Kampar Tahun 2015. Waktu penelitian dilaksanakan pada bulan Maret-Juli 2015.

Setelah data dikumpulkan, maka langkah selanjutnya adalah mengolah data yang terdiri dari beberapa langkah, yaitu editing, coding, entry, processing, dan cleaning. Analisis data dalam penelitian ini adalah Univariat dan bersifat deskriptif. Semua variabel secara deskriptif dengan menggunakan komputer untuk menghitung frekuensi dan persentasenya. Hasil pengolahan disajikan dalam tabel distribusi frekuensi dan persentase. Analisis data dilanjutkan dengan membahas hasil penelitian dengan menggunakan teori kepustakaan yang ada kemudian diberi nilai sesuai dengan kategori yang ditentukan.

\section{HASIL DAN PEMBAHASAN}

Pada analisa univariat didapakan hasil mayoritas berumur 60-74 tahun sebanyak 31 orang $(68.9 \%)$. Berdasarkan jenis kelamin responden adalah 28 orang (62.2\%). Berdasarkan pendidikan responden SD sebanyak 21 orang (46.7\%). Berdasarkan pekerjaan responden IRT sebanyak 21 orang (46.7\%). Berdasarkan jenis gigi tiruan responden GTLL sebanyak 23 orang (51.1\%). mayoritas responden memiliki pengetahuan yang baik yaitu sebanyak 23 orang (51.1\%). mayoritas responden memiliki kualitas hidup yang yang rendah yaitu sebanyak 26 orang $(57.8 \%)$.

Tabel 1

Analisis Univariat

\begin{tabular}{lcc}
\hline \multicolumn{1}{c}{ Variabel } & Frekuensi & (\%) \\
\hline Umur & & \\
$60-74$ tahun & 31 & 68.9 \\
$75-90$ tahun & 13 & 28.9 \\
>90 tahun & 1 & 2.2 \\
Jenis Kelamin & & \\
Laki-laki & 17 & 37.8 \\
Perempuan & 28 & 62.2 \\
Pendidikan & & \\
Tidak tamat SD & 8 & 17.8 \\
SD & 21 & 46.7 \\
SMP & 12 & 26.7 \\
SMA & 3 & 6.7 \\
Perguruan Tinggi & 1 & 2.2 \\
Pekerjaan & & \\
Swasta & 6 & 13.3 \\
Wiraswasta & 0 & 0 \\
Tani & 12 & 26.7 \\
IRT & 21 & 46.7 \\
Pensiunan PNS & 1 & 2.2 \\
Lain-lain & 5 & 11.1 \\
Jenis Gigi Tiruan & & \\
GTSL & 21 & 46.7 \\
GTLL & 23 & 51.1 \\
Cekat & 1 & 2.2 \\
Pengetahuan & & \\
Baik & 23 & 51.1 \\
Kurang Baik & 22 & 48.9 \\
Kualitas Hidup & & \\
Tinggi & 19 & 42.2 \\
& & \\
\hline
\end{tabular}




\begin{tabular}{ccc}
\hline Variabel & Frekuensi & $\mathbf{( \% )}$ \\
\hline Rendah & 26 & 57.8 \\
\hline
\end{tabular}

\section{Umur}

Berdasarkan hasil penelitian mayoritas umur responden yang memakai gigi tiruan berumur 60-74 tahun sebanyak 31 orang (68.9\%). Umur sangat berpengaruh pada pengetahuan yang mereka miliki, hal ini di dukung oleh teori Notoatmodjo (2007) bahwa usia mempengaruhi daya tangkap dan pola pikir seseorang. Semakin bertambah usia seseorang akan semakin berkembang pula daya tangkap dan pola pikirnya, sehingga pengetahuan yang diperoleh semakin membaik.

Berdasarkan penelitian yang dilakukan oleh Padu (2014) di Kecamatan Tondano Barat bahwa umur sangat berpengaruh terhadap kualitas pengetahuan seseorang individu. Umur merupakan salah satu kedewasaan fisik dan kematangan fisikologis yang berkaitan dalam memberikan tanggapan atau respon terhadap objek sekitarnya. Hal ini bisa dilihat dari 67 responden yaitu 24-26 tahun sebanyak 22 responden $(32,84 \%)$, dan sedikit rentang usia 18-20 tahun yaitu 11 responden (16,41\%).

Umur adalah umur individu yang terhitung mulai saat dilahirkan sampai berulang tahun. Sedangkan semakin cukup umur, tingkat kematangan dan kekuatan seseorang akan lebih matang dalam berfikir dan bekerja. Dari segi kepercayaan masyarakat, seseorang yang lebih dewasa dipercaya dari orang yang belum tinggi kedewasaannya. Hal ini akan sebagian dari pengalaman dan kematangan jiwa Nursalam (2003) dalam A. Wawan dan Dewi M (2010).

Menurut asumsi peneliti, yang berumur 6074 tahun yang lebih banyak memakai gigi tiruan dikarenakan mereka lebih mengutamakan akan kesehatan rongga mulut, ingin sekali memperbaiki fungsi fonetik dan estetik agar menjadi lebih baik. Oleh karena itu diharapkan, setiap individu yang memakai gigi tiruan tidak harus memperhatikan umur. Selain para lansia, masyarakat yang berusia muda juga bisa memakai gigi tiruan agar lebih memperhatikan kesehatan rongga mulut.

\section{Jenis Kelamin}

Berdasarkan hasil penelitian mayoritas jenis kelamin responden perempuan sebanyak 28 orang $(62.2 \%)$, sedangkan responden lakilaki sebanyak 17 orang $(37.8 \%)$. Hal ini menunjukan responden pada desa sibuak kecamatan tapung kabupaten kampar tahun 2015 lebih banyak yang memakai gigi tiruan para perempuan.

Berdasarkan penelitian yang dilakukan oleh Padu (2014) di Kecamatan Tondano Barat bahwa jenis kelamin sangat berpengaruh terhadap karakteristik dalm penelitian. Hal ini bisa dilihat dari 67 responden, jenis kelamin yang banyak laki-laki yaitu 30 responden $(58,21 \%)$.

Faktor jenis kelamin merupakan salah satu variabel desktriptif yang dapat memberikan perbedaan antara angka/rate kejadian pada pria dan wanita. Dalam hal perbedaan jenis kelamin harus di pertimbangkan pula variabel lain seperti umur atau variabel lainnya mempunyai variabel lainnya yang mempunyai perbedaan penyebaran menurut jenis kelamin Nursalam (2003) dalam A. Wawan dan Dewi M (2010).

Menurut asumsi peneliti, jenis kelamin sangat berperan dalam menentukan perbandingan pengguna gigi tiruan antara perempuan dan laki-laki. Dari hasil penelitian, perempuan lebih banyak menggunakan gigi tiruan karena perempuan lebih perduli akan kesehatan jaringan mulut dan ingin sekali mencegah kerusakan lebih lanjut pada rongga mulutnya dari pada para lelaki. Oleh karena itu diharapkan, apapun jenis kelaminnya jika kehilangan gigi segeralah menggantikan gigi yang hilang dengan gigi tiruan agar kesehatan rongga mulut bagi penderita edentolus tetap terjaga dengan baik.

\section{Pendidikan}

Berdasarkan hasil penelitian, menunjukan bahwa responden dengan tingkat pendidikan SD sebanyak 21 orang (46.7\%) lebih banyak dibandingkan PT (Perguruan Tinggi) hanya sejumlah 1 orang $(2.2 \%)$.

Berdasarkan penelitian yang dilakukan oleh Padu (2014) di Kecamatan Tondano Barat 
bahwa tingkat pendidikan paling banyak merupakan lulusan SMA dengan jumlah 35 responden $(52,24 \%)$ dan yang paling sedikit yaitu lulusan SD dengan jumlah 6 responden $(8,96 \%)$.

Pendidikan dapat mempengaruhi seseorang termasuk juga perilaku seseorang akan pola hidup terutama dalam memotivasi untuk sikap berperan serta dalam pembangunan Notoatmodjo (2003) dalam A. Wawan dan Dewi M (2010).

Menurut asumsi peneliti, jika pendidikan hanya sampai tingkat SD maka seseorang akan cenderung kesulitan dalam mendapatkan informasi. Oleh karena itu pendidikan mempengaruhi proses belajar, semakin tinggi pendidikan seseorang semakin mudah orang tersebut untuk menerima informasi. Semakin banyak informasi yang masuk semakin banyak pula pengetahuan yang didapat termasuk pengetahuan tentang gigi tiruan, pemilihan gigi tiruan, dan informasi kesehatan rongga mulut, terutama kesehatan tentang gigi tiruan. Oleh karena itu diharapkan, tidak semua orang yang berpendidikan tinggi yang dapat mengetahui tentang gigi tiruan. Akan tetapi bagi yang tidak berpendidikan tinggi juga bisa belajar, mencari tau informasi dari manapun tentang gigi tiruan, jenis gigi tiruan maupun manfaat dari pemakaian gigi tiruan tersebut.

\section{Pekerjaan}

Berdasarkan hasil penelitian mayoritas responden IRT sebanyak 21 orang (46.7\%). Sedangkan pensiunan PNS lebih redah sebanyak 1 orang (2.2\%). Dapat disimpulkan hampir semua responden dari mereka adalah ibu rumah tangga dan tidak bekerja, dan jika pun bekerja hanya dilingkungan rumah. Lingkungan dimana tempat responden tinggal masyarakat, keluarga dan penduduk lainnya, sehingga pengetahuan tentang gigi tiruan yang didapat responden sumber dari interaksi antar mereka.

Pekerjaan adalah kegiatan yang harus dilakukan terutama untuk menunjang kehidupannya dan kehidupan keluarga. Pekerjaan bukanlah sumber kesenangan, tetapi lebih banyak merupakan cara mencari nafkah yang membosankan, berulang dan banyak tantangan. Sedangkan bekerja umumnya merupakan kegiatan yang menyita waktu. Bekerja bagi ibu-ibu akan mempunyai pengaruh terhadap kehidupan keluarga Nursalam (2003) dalam A. Wawan dan Dewi M (2010).

Menurut asumsi peneliti, pengguna gigi tiruan yang tidak bekerja seperti IRT memiliki waktu yang cukup untuk mencari informasi tentang kesehatan gigi tiruan atau kesehatan rongga mulut melalui berbagai cara salah satunya, melalui media elektronik, yang hasilnya menambah pengetahuan mereka tentang gigi tiruan. Oleh karena itu diharapkan, bagi yang tidak memiliki pekerjaan seperti Ibu Rumah Tangga untuk mendapatkan informasi tentang gigi tiruan tidak cukup diperoleh dari media elektronik dan lingkungan tempat tinggal saja, sebaiknya untuk mendapatkan informasi lebih banyak tentang gigi tiruan bisa di dapat dari luar ruang lingkup tempat tinggal, terutama bisa mendapatkan informasi dari orang yang memiliki pekerjaan.

\section{Jenis Gigi Tiruan}

Berdasarkan hasil penelitian mayoritas jenis gigi tiruan responden GTLL sebanyak 23 orang $(51.1 \%)$. Hal ini menentukan bahwa sebagian besar lansia yang berada di desa sibuak kecamatan tapung kabupaten kampar lebih banyak kehilangan seluruh gigi rahang atas dan bawah.

Menurut Adi (2008) dalam Meutuah (2009), secara umum gigi palsu pada dunia kedokteran gigi lebih dikenal sebagai gigi tiruan dibedakan menjadi dua yaitu Gigi Tiruan Lepasan (GTL), dan Gigi Tiruan Cekat (GTC). Gigi tiruan lepasan adalah gigi tiruan yang dapat dilepas dan di pasang oleh pengguna. Sedangkan gigi tiruan cekat adalah gigi tiruan yang tidak dapat dilepas atau dipasang sendiri oleh pengguna.

Menurut asumsi peneliti, sebagian besar lansia yang berada di Desa Sibuak memakai jenis gigi tiruan lengkap lepasan guna untuk menggantikan gigi yang hilang agar dapat memperbaiki fungsi fonetik, estetik dan lain- 
lain sehingga para lansia lebih perduli akan kesehatan rongga mulutnya. Oleh karena itu diharapkan, pemakaian gigi tiruan tidak tergantung dengan pemilihan jenis gigi tiruannya saja tetapi sebaiknya dalam pemilihan jenis gigi tiruan juga harus sesuai dengan segi kenyaman masing-masing dari para pemakai gigi tiruan tersebut.

\section{Pengetahuan}

Berdasarkan dari hasil penelitian menunjukan bahwa dari 45 responden, mayoritas berpengetahuan baik sebanyak 23 orang $(51.1 \%)$. Pengetahuan baik lansia terdapat pada bagian kuesioner pernyataan tentang pengertian gigi tiruan, sedangkan pengetahuan yang kurang baik terdapat pada bagian kuesioner pernyataan tentang membersihkan gigi tiruan dapat menggunakan sabun cair.

Menurut Padu (2014), pengetahuan sangat erat kaitannya dengan pendidikan, dimana diharapkan seseorang dengan pendidikan tinggi akan semakin luas pengetahuanya. Pendidikan merupakan faktor penting yang menjadi salah satu dasar pada pengetahuan seseorang. Pernyataan ini tidak serta merta menjadi jaminan bahwa orang dengan lulusan perguruan tinggi mempunyai pengetahuan yang lebih baik dibanding yang bukan lulusan perguruan tinggi, salah satunya pengetahuan mengenai kesehatan gigi dan mulut.

Menurut asumsi penelitian gambaran pengetahuan lansia tentang gigi tiruan cukup baik, terutama pengetahuan tentang fungsi gigi tiruan. Tetapi ada sebagian lansia yang tidak mengetahui apa itu gigi tiruan, dan tidak merasa cemas atau perihatin mengenai masalah gusi dan gigi tiruannya. Dengan adanya sikap seperti itu dapat mempengaruhi kurangnya kesadaran lansia untuk memperhatikan akan kesehatan gigi dan mulut terutama kesehatan gigi tiruannya. Oleh karena itu diharapkan, sebaiknya para lansia harus diberikan informasi lebih jauh dan luas tentang gigi tiruan, dengan cara bekerjasama dengan dokter gigi atau petugas kesehatan gigi untuk melakukan penyuluhan agar lebih meningkatkan mutu kesehatan gigi dan mulut terutama kesehatan gigi tiruan pada lansia yang memakai gigi tiruan.

\section{Kualitas Hidup}

Berdasarkan dari hasil penelitian menunjukan bahwa dari 45 responden, mayoritas kualitas hidup sebanyak 19 orang (42.2\%). Kualitias hidup tertinggi lansia terdapat pada bagian kuesioner pernyataan setiap yang menggunakan gigi tiruan sering membatasi jumlah atau jenis makanan yang dikonsumsi karena masalah dengan gigi tiruan dan menggunakan gigi tiruan mengembalikan rasa percaya diri. Sedangkan kualitas hidup lansia yang terendah terletak pada bagian kuesioner pernyataan merasa gugup atau rendah diri dikarenakan memakai gigi tiruan.

Kualitas hidup adalah persepsi seseorang dalam konteks budaya dan norma yang sesuai dengan tempat hidup orang tersebut, serta berkaitan dengan tujuan, harapan, standar, dan kepedulian selama hidupnya (Rawiyah, 2014).

Menurut asumsi peneliti, kualitas hidup adalah suatu hasil dari tujuan hidup, atau apa yang diharapan untuk kebaikan diri sendiri serta keinginan meraih hidup yang lebih baik. Untuk mendapatkan hidup yang lebih baik sebagian lansia yang kehilangan gigi menyadari untuk segera menggantikan gigi yang hilang dengan gigi palsu. Tujuan mereka agar dapat mengembalikan fungsi pengunyahan, bicara dan fungsi estetik maupun menjaga kesehatan rongga mulut. Oleh karena itu diharapkan, sebaiknya para lansia harus lebih perduli atau memperhatikan kesehatan rongga mulutnya, dan juga tidak sekedar untuk mementingkan diri sendiri, tetapi para lansia juga bisa memberikan informasi kepada masyarakat lain bagaimana manfaat gigi tiruan supaya mendapatkan kualitas hidup yang baik secara fungsional maupun optimal.

\section{KESIMPULAN DAN SARAN}

\subsection{Kesimpulan}

Karakteristik responden dibagi atas umur, jenis kelamin, pendidikan, pekerjaan, dan jenis gigi tiruan yang digunakan lansia. Total 
responden 45 orang dengan sebagian besar umur responden adalah berumur 60-74 tahun sebanyak 31 orang $(68.9 \%)$. Berdasarkan jenis kelamin responden adalah 28 orang (62.2\%). Berdasarkan pendidikan responden SD sebanyak 21 orang (46.7\%). Berdasarkan pekerjaan responden IRT sebanyak 21 orang (46.7\%). Berdasarkan jenis gigi tiruan responden GTLL sebanyak 23 orang (51.1\%). Pengetahuan lansia tentang gigi tiruan adalah mayoritas responden memiliki pengetahuan baik yaitu sebanyak 23 orang (51.1\%). Kualitas Hidup lansia yang menggunakan gigi tiruan adalah mayoritas responden memiliki kualitas hidup rendah yaitu sebanyak 26 orang (57.8\%).

\subsection{Saran}

Diharapkan kepada seluruh masyarakat lansia di Desa Sibuak Kecamatan Tapung Kabupaten Kampar untuk dapat bekerjasama dengan dokter gigi atau petugas kesehatan gigi untuk meningkatkan mutu kesehatan gigi dan mulut terutama kesehatan gigi tiruan pada lansia yang menggunakan gigi tiruan di Desa Sibuak Kecamatan Tapung Kabupaten Kampar. Kepada institusi pendidikan diharapkan dapat menambah referensi tentang gigi tiruan khususnya tentang penelitian ini sehingga lebih mudah bagi peneliti selanjutnya. Untuk peneliti selanjutnya dalam melakukan penelitian diharapkan agar dapat menambah referensi atau sumber untuk mendukung penelitian agar lebih baik lagi dan dapat memilih judul sesuai yang berhubungan dengan gambaran pengetahuan dan kualitas hidup lanjut usia yang menggunakan gigi tiruan

\section{DAFTAR PUSTAKA}

A. Wawan dan Dewi M. (2010). Teori \& pengukuran pengetahuan sikap dan perilaku manusia, Yogyakarta : Nuha Medika

Buku Ajar Boedhi-Darmojo. (2010). Geriatri (Ilmu Kesehatan Usia Lanjut), Jakarta : Balai Penerbit FKUI

Fonda Padu. (2014). Gambaran Tingkat Pengetahuan Masyarakat Terhadap Pemakaian Gigi Tiruan Di Kecamatan Tondano Barat

Haryanto dkk. (1991). Ilmu geligi sebagian lepasan, Jakarta : Hipokrates

Muzdalifah Solina Berutu (2014). Pengaruh Penggunaan Gigitiruan Penuh Terhadap Kualitas Hidup Manula Di Kota Makassar

Sarnizia Meutuah. (2009). Hubungan Karakteristik Pengguna Gigi Palsu Dengan Pemanfaatan Jasa Tukang Gigi Di Kota Medan Tahun 2008

Soekidjo Notoatmodjo. (2005). Metodologi Penelitian Kesehatan, Jakarta : Rineka Cipta

Soekidjo Notoatmodjo. (2007). Promosi Kesehatan dan Ilmu Perilaku. Jakarta : Rineka Cipta

Soekidjo Notoatmodjo. (2010). Ilmu Perilaku Kesehatan, Jakarta: Rineka Cipta

Soekidjo Notoatmodjo. (2012). Meteologi Penelitian Kesehatan. Jakarta : Rineka Cipta

Ummul Rawiyah. (2014). Perbedaan Kualitas Hidup Manula Pengguna Dan Bukan Pengguna Gigi Tiruan Penuh Di Kota Makassar. 